\title{
An attempt to the nondestructive investigation of photo-induced potato postharvest quality degradation - Preliminary results
}

\author{
VIKTÓRIA ZSOM-MUHA ${ }^{1}$, LIEN LE PHUONG NGUYEN ${ }^{2,3}$, \\ LÁSZLÓ BARANYAI ${ }^{1}$, GÉZA HITKA ${ }^{4}$, ZSUZSANNA HORVÁTH-MEZŐFI ${ }^{4}$, \\ GERGÖ SZABÓ ${ }^{4}$ and TAMÁS ZSOM ${ }^{4 *}$
}

${ }^{1}$ Department of Food Measurement and Process Control, Institute of Food Science and Technology, Hungarian University of Agriculture and Life Sciences, Somlói út 14-16. H-1118, Budapest, Hungary

${ }^{2}$ Department of Livestock Product and Food Preservation Technology, Institute of Food Science and Technology, Hungarian University of Agriculture and Life Sciences, Ménesi út 43-45. H-1118, Budapest, Hungary

${ }^{3}$ Institute of Biotechnology and Food Technology, Industrial University of Ho Chi Minh City, Ho Chi Minh 700 000, Vietnam

${ }^{4}$ Department of Postharvest, Supply Chain, Commerce and Sensory Science, Institute of Food Science and Technology, Hungarian University of Agriculture and Life Sciences, Ménesi út 43-45. H-1118, Budapest, Hungary

\section{CONFERENCE FULL PAPER}

Received: May 14, 2021 Accepted: August 9, 2021

Published online: August 30, 2021

(C) 2021 The Author(s)

\begin{abstract}
Among improper harvest and/or postharvest storage conditions, the effect of direct sunlight plays an important role in quality degradation of potato resulting in the development of green surface color based on chlorophyll formation associated with the formation of poisonous chemicals - glycoalcaloids - known as $\alpha$-chaconine and $\alpha$-solanine. Yellow skinned and fleshed potatoes with or without visible initial marks of green surface color were stored at normal room temperature under direct natural (sun)light conditions for almost two months. The aim of this study was the preliminary investigation of the sunlight induced
\end{abstract}

*Corresponding author. E-mail: zsom.tamas@uni-mate.hu 
formation of chlorophyll related compounds in potato indirectly by the detection of chlorophyll development. This attempt was based on nondestructive determination of chlorophyll related spectral and fluorescence indices for both sunlight exposed and unexposed potato sides. For both potato groups the chlorophyll content related DA-index ${ }^{\circledR}$ and chlorophyll fluorescence characteristics $\left(\mathrm{F}_{0}, \mathrm{~F}_{\mathrm{m}}, \mathrm{F}_{\mathrm{v}}\right.$ and $\left.\mathrm{F}_{\mathrm{v}} / \mathrm{F}_{\mathrm{m}}\right)$ increased during the storage period representing chlorophyll formation. In the case of $F_{m}, F_{v}$ and $F_{v} / F_{m}$ values, the yellow samples reached the values of the initial spotted green samples by the $7^{\text {th }}-9^{\text {th }}$ days. From this time, the chlorophyll fluorescence values changed only minimally. After storage day 34 , in the case of both at day 0 yellow and green spotted potatoes, the sunny side's $\mathrm{F}_{0}$ value was lower than that of shaded side. Close relationship was found between the results of Walz monitoring-PAM (Pulse AmplitudeModulated) chlorophyll fluorometer and the PSI (Photon Systems Instruments) chlorophyll fluorescence imaging device (e.g. $\mathrm{F}_{\mathrm{v}} \mathrm{R}^{2}=0.7226$ ). According to our preliminary results, the Vis/NIR DA-meter ${ }^{\mathbb{R}}$, the monitoring-PAM and the chlorophyll fluorescence imaging fluorometers were found to be suitable nondestructive devices for further investigations concerning the postharvest chlorophyll formation based greening phenomena, which is associated with solanine development in potato.

\section{KEYWORDS}

Solanum tuberosum, greening, photosynthetically active chlorophyll, fluorescence, solanine, DA-index ${ }^{\circledR}$, DA-meter ${ }^{\circledR}$

\section{INTRODUCTION}

Potato (Solanum esculentum L.) plays a major role in human diet and potato based food production. As one of the major vegetables, potato may suffer significant quality decrease under improper conditions before, during and after harvest, during its storage operations, even during marketing and shelf-life. The effect of indirect and/or direct sunlight exposure plays an important role in overall and internal quality degradation. From the postharvest and nutritional point of view, potato quality change is closely related to the photo-induced formation of specific potato glycoalkaloids (GAs), namely $\alpha$-chaconine and $\alpha$-solanine (Abbasi et al., 2016; Grunenfelder, 2005; Machado et al., 2007; Sengül et al., 2004; Tanios et al., 2020). All green parts of the potato plant contain toxic solanine in higher concentrations for natural protective purposes against pests. The edible part of the plant, the tuber, may normally contain solanine as well, but in much lower concentrations (Barceloux, 2009). Due to the sunlight induced formation of these toxic compounds, and accumulation (mainly in and close to the potato skin), the consumption and possible food industrial use of freshly harvested and/or not properly stored potato may be hazardous for human health.

The estimated highest safe level of total GAs for human consumption (safe oral dose for humans) is about $1 \mathrm{mg} \mathrm{kg}^{-1}$ body weight. Acute toxicity may be caused at a level of 1$1.75 \mathrm{mg} \mathrm{kg}^{-1}$ and a potential lethal dose is from $2-5$ to $3-6 \mathrm{mg} \mathrm{kg}^{-1}$ body weight, respectively (Friedman, 2006; Ordóñez-Vásquez et al., 2019). The safe upper limit for human consumption recommended by the FAO and the WHO is $1 \mathrm{mg} \mathrm{kg}^{-1}$ of body weight and $200 \mathrm{mg} \mathrm{kg}^{-1} \mathrm{GAs}$ (Ordóñez- Vásquez et al., 2019) fresh potato weight. The detection of potato GAs content is primarily based on analytical chemistry methods (chromatography, spectrometry, etc.) (e.g. Abbasi et al., 2016; Babazadeh et al., 2016; Grunenfelder et al., 2006; Kjær et al., 2017; Machado et al., 2007; Matsuda et al., 2004; Sengül et al., 2004). There is a great need for rapid detection of 
the presence of chlorophyll associated GAs, basically for the solanine formation. It may be evaluated indirectly and non-destructively by several nondestructive methods, based on imaging and spectroscopy techniques (e.g. laser-induced light backscattering imaging \& digital imaging Babazadeh et al., 2016, 2020; fluorometric analysis - Bianchi et al., 2014; image processing Ebrahimi et al., 2011; hyperspectral imaging - Kjær et al., 2017; imaging and spectroscopy review - Sanchez et al., 2020; Vis/NIR spectrometry - Tilahun et al., 2020).

The aim of our experiment was to test the ability and the possible applicability of nondestructive optical methods in order to follow and detect indirectly the sun-induced greening related solanine formation of potato referred to chlorophyll formation and detection. For this purpose, photosynthetically active chlorophyll content related quality parameters were evaluated by chlorophyll fluorescence analysis and imaging, and chlorophyll content related DA-index ${ }^{\circledR}$ was also measured. Additionally, other non-destructive quality parameters as textural quality properties (acoustic stiffness and impact firmness) were also determined according to Felföldi et al. (2017) and Zsom-Muha and Felföldi (2007).

\section{MATERIALS AND METHODS}

In our preliminary study, altogether nine pieces of yellow peeled potatoes (Solanum tuberosum cv. Pannónia) were measured during 59 storage days. Samples were collected from a loose load of commercial potatoes from a local shop. In order to have distinctive sample groups, five pieces of the samples showed spot-like greenish (skin) surface (dis)coloration right at the beginning of the experiment (spotted green group). The remaining four pieces were collected as unaffected by greening phenomena (yellow group). All tubers were stored at room temperature in LDPE bags without shading and they were exposed to natural sunlight.

Chlorophyll activity and content related data were nondestructively collected on each measurement day. For fluorometric data collection, a PAM WinControl-3 controlled monitoring-PAM (Pulse Amplitude-Modulated) fluorometer equipped with a Moni-Head/485 emitter-detector head (Heinz Walz GmbH, Germany) and a FluorCam7 (version 1.2.5.18) controlled PSI Open FluorCam FC 800-O/2020 (Photon Systems Instruments, Czech Republic) imaging chlorophyll fluorometer were used. The PSI Open FluorCam system provides not just spot-like, but overall chlorophyll fluorescence data of the selected sample surface (Fig. 7) contrary to the monitoring-PAM fluorometer. The greening associated chlorophyll formation closely referring also to changes in photosynthetic activity, integrity and efficiency of photosystem II (PSII) were characterized by the determination of chlorophyll fluorescence parameters. $\mathrm{F}_{0}$ (dark fluorescence signal), $\mathrm{F}_{\mathrm{m}}$ (maximum dark fluorescence signal) and $\mathrm{F}_{\mathrm{v}}$ (variable fluorescence, $F_{m}-F_{0}$ ) parameters were measured or calculated in the case of potato samples dark adapted an hour before the actual measurements. The calculated index of $\mathrm{F}_{\mathrm{v}} / \mathrm{F}_{\mathrm{m}}$ reflects the potential maximum photon yield of photochemistry, i.e. the maximum photochemical efficiency of a photosynthetically active chlorophyll-containing sample (Gorbe and Calatayud, 2012). It is a valuable tool to determine both photosynthetic capacity, stability and to follow e.g. the maturity related chlorophyll degradation (Zsom et al., 2020) or the negative quality effect of external factors such as low storage temperature (Zsom et al., 2018).

Additionally, a Sintéleia DA-meter ${ }^{\circledR}$ ver. 3.4 controlled FRM01-F type Vis/NIR DA-meter ${ }^{\circledR}$ (Sintéleia s.r.l., Italy) was used for nondestructive spectral data collection. This chlorophyll 
content related maturity index (index of absorbance difference, $\mathrm{I}_{\mathrm{AD}}$ ) called DA (or $\Delta \mathrm{A}$ ) index ${ }^{\circledR}$ is calculated upon the difference in absorbance between the wavelengths of 670 and $720 \mathrm{~nm}$ near the chlorophyll-a absorption peak. The value of DA-index ${ }^{\circledR}$ varying from 0 to 5 is proportional to the amount of active chlorophyll existing in the sample (Ziosi et al., 2008).

Mass, acoustic stiffness $\left(\mathrm{S}=\mathrm{f}^{2} * \mathrm{~m}^{*} 10^{-6}, \mathrm{~N}^{*} \mathrm{~mm}^{-1}\right)$ and impact firmness $\left(\mathrm{D}, \mathrm{ms}^{-2}\right)$ were determined by a table-top firmness measuring device called AWETA AFS Desktop System (AWETA AFS DTF V0.0.0.105, The Netherlands).

Potatoes were measured at their two opposite sides (sunny and shaded side) and were kept by their sunny side facing upwards during storage. Three different and equally distributed measurement points along the equator of the potato were selected per side. These six individual points were used for DA-meter ${ }^{\circledR}$ measurements and for chlorophyll fluorescence measurements by the Walz monitoring-PAM fluorometer in order to characterize the change in surface color related chlorophyll content during storage. Each measurement day 54 points were measured in total. In the case of acoustic stiffness (S) and impact firmness (D) measurements, the middle part of each potato side was measured by the AWETA system. The averages of these sampling points were plotted in our figures. In the case of PSI Open FluorCam chlorophyll fluorescence imaging device, the individual sunny and shaded sides were used for data collection providing the $\mathrm{F}_{0}, \mathrm{~F}_{\mathrm{m}}$, $\mathrm{F}_{\mathrm{v}}$ and $\mathrm{F}_{\mathrm{v}} / \mathrm{F}_{\mathrm{m}}$ fluorescence parameters as indirect internal quality indices and they were individually evaluated for each side of each potato.

Data were converted by means of routines in MS-Excel and were analyzed using the SPSS for Windows (ver. 14) software. Results are presented in figures with mean and bars represent confidence interval (CI) for mean (95\% CI). Statistical analysis was performed at 95\% significance level $(\alpha=0.05)$. ANOVA tests were carried out to evaluate the effect of factors of natural illumination and storage time at $P<0.05$. The one-way ANOVA F value was used to compare effects to the natural variability of collected data.

\section{RESULTS AND DISCUSSION}

Due to the storage conditions of room temperature and moderate relative humidity provided by LDPE bags, textural changes were observed as shown in Figs 1-3. At 95\% significance level, difference was found concerning initial texture properties between the two greening stages (initially yellow and initially spotted green) in the case of both texture parameters (S and D). This significant difference was observed until day 34 of the storage in the case of both texture measurement methods (Fig. 1a and b). Due to the applied (improper) storage conditions, these textural changes were significantly affected by mass loss increase. Generally, the initially yellow group's average mass loss showed lower value in contrast to the initially green group, however, these differences were not significant (Fig. 2).

Due to the homogeneous structure of the potato, the overall (global) structure described by acoustic stiffness is really close to the surface firmness described by the impact method (Fig. 1). Figure 3 shows the relationship between acoustic stiffness (S) and impact firmness coefficient (D). This relationship can be described by an exponential function $\left(\mathrm{R}^{2}=0.7416\right)$. Contrary to this close relationship between the acoustic stiffness (S) and impact firmness coefficient, such a relation is not entirely valid for inhomogeneous structured commodities like tomato and pepper 


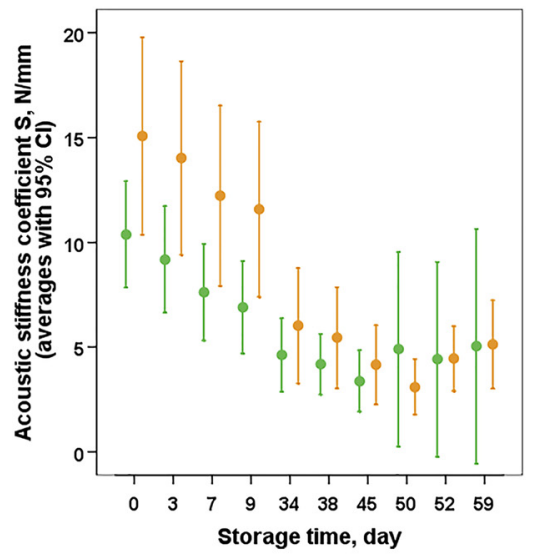

a)

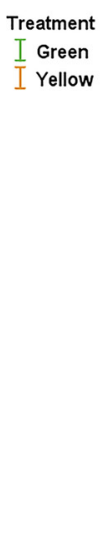

Fig. 1. Change of a) acoustic stiffness coefficient $\left(\mathrm{S}, \mathrm{N}^{*} \mathrm{~mm}^{-1}\right)$ and $\left.\mathrm{b}\right)$ impact firmness coefficient $\left(\mathrm{D}, \mathrm{ms}^{-2}\right)$ of potato samples during storage.

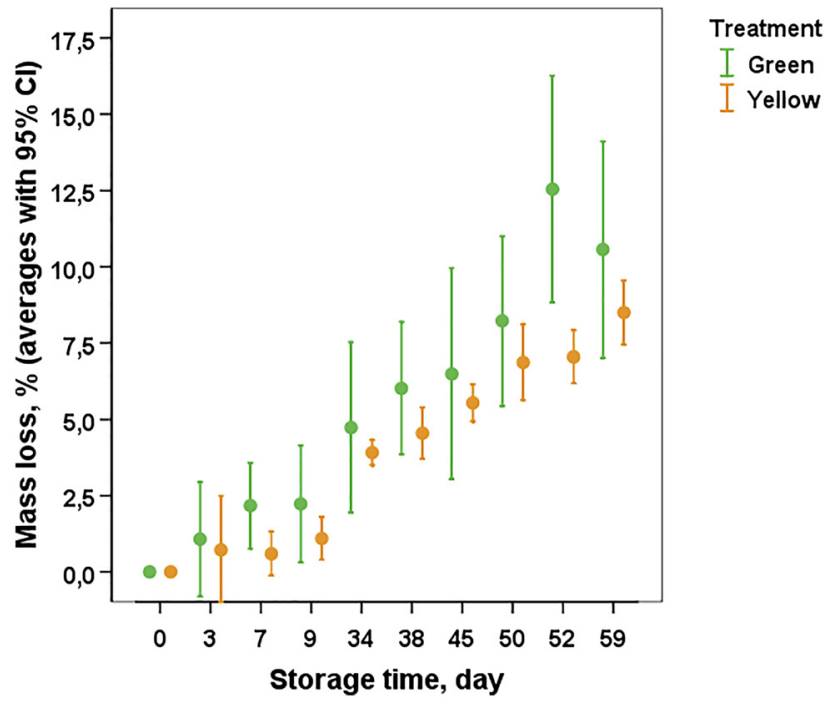

Fig. 2. Mass loss (\%) change of potato samples during storage.

(Zsom et al., 2020). Based on the relationship shown in Fig. 3, the textural changes are sensibly described even by the results of the acoustic method or the impact method.

Really impressive results are shown in Fig. 4, describing the chlorophyll content related changes during natural sunlight induced artificial greening of potato followed by the DA-meter ${ }^{\circledR}$ measurement. The applied method was found to be sensitive in order to distinguish the difference between groups. Initially yellow and initially spotted green samples' DA-index ${ }^{\circledR}$ was 


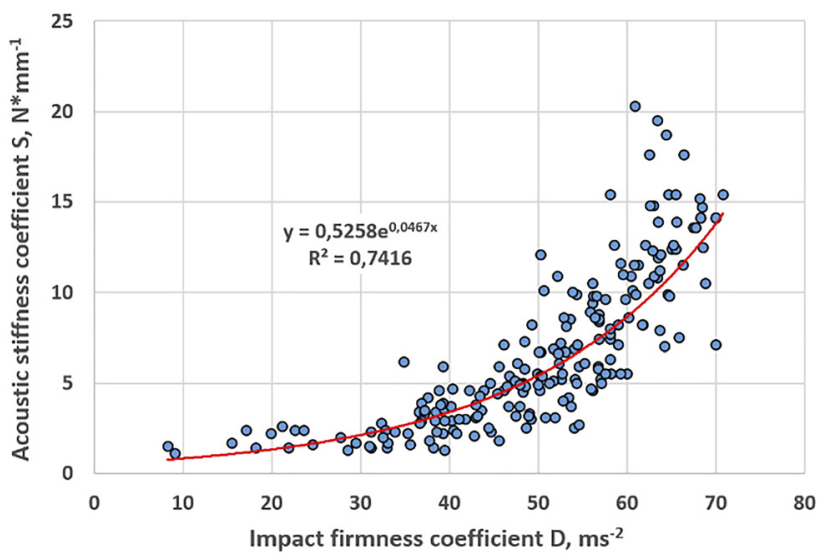

Fig. 3. Relationship between acoustic stiffness coefficient (S) and impact firmness coefficient (D) of potato samples during storage.

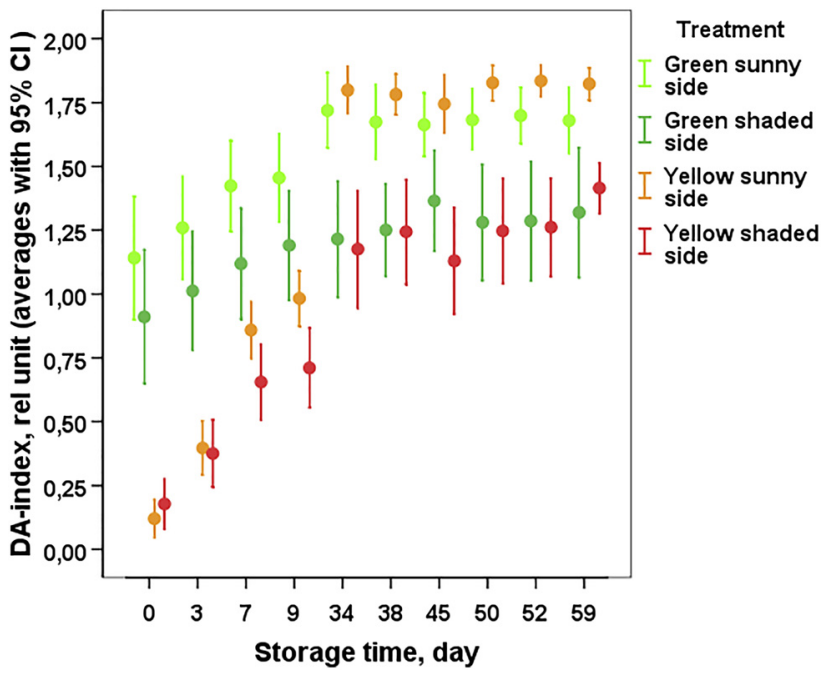

Fig. 4. Change of DA-index ${ }^{\circledR}$ of potato samples measured by the Sintéleia FRM01-F type Vis/NIR DAmeter $^{\mathbb{R}}$ during storage.

significantly different, the mean was $0.90-1.14$ in the case of greenish sample and $0.12-0.17$ relative unit in the case of yellow samples. In the case of initially spotted green samples, the shaded sides' DA-index ${ }^{\circledR}$ was lower than that of the sunny side's. The difference between the two sides became significant from day 34 .

The initially yellow groups' DA-index ${ }^{\circledR}$ increased continuously during the storage clearly referring to the sunlight induced chlorophyll content increase. The difference between the sunny and shaded side became significant by day 9 . In the case of both groups, significant difference 
was observed between the two sides from day 34. From day 34, the initial difference of the two groups simply vanished suggesting having reached the same green status. Remarkably, from day 34, significant difference was found between the sunny and the shaded sides, independently of the group, but not between the initially yellow and initially spotted green groups. The DA-in$\operatorname{dex}^{\circledR}$ of the sunny side was about 1.75 , and the shaded side was about 1.25 , respectively. After day 34 , the DA-index ${ }^{\circledR}$ value changed only minimally.

In the case of the Walz monitoring-PAM and PSI Open FluorCam chlorophyll fluorescence devices, the changes in the $\mathrm{F}_{\mathrm{m}}$ and $\mathrm{F}_{0}$ values are shown in Figs 5 and 6 . The different groups' $\mathrm{F}_{\mathrm{m}}$, $\mathrm{F}_{0}, \mathrm{~F}_{\mathrm{v}}$ (not shown) and $\mathrm{F}_{\mathrm{v}} / \mathrm{F}_{\mathrm{m}}$ (not shown) values differed significantly in the beginning. Both

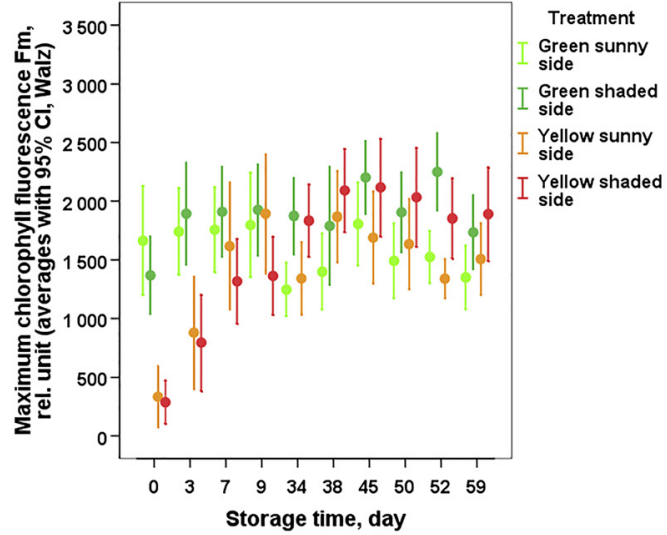

a)

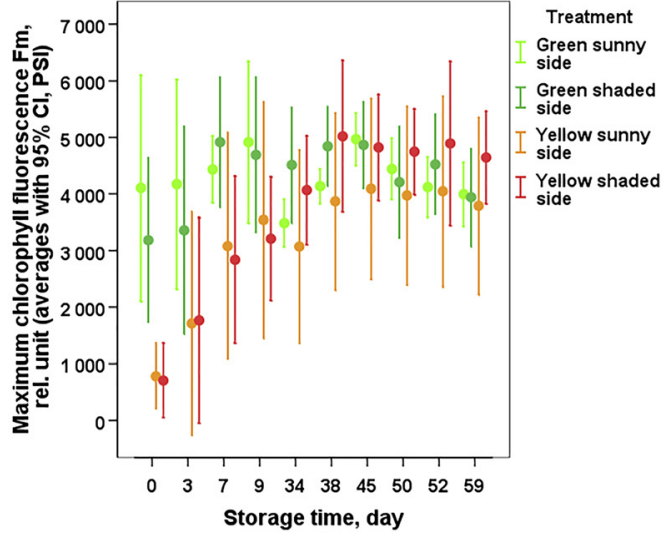

b)

Fig. 5. Change of maximum chlorophyll fluorescence values $\left(\mathrm{F}_{\mathrm{m}}\right)$ of potato samples measured by a) the Walz monitoring-PAM device and b) by the PSI Open FluorCam device during storage.

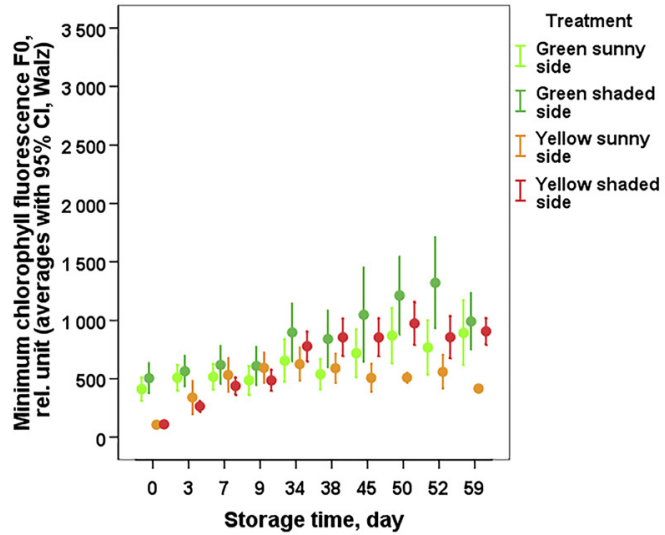

a)

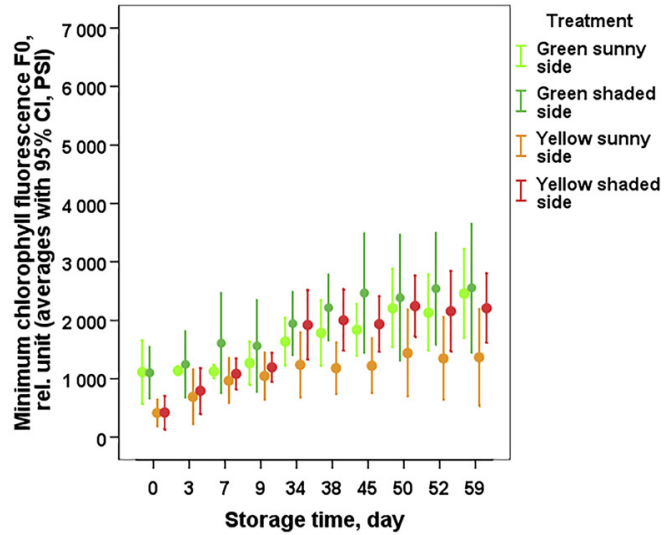

b)

Fig. 6. Change of minimum chlorophyll fluorescence values $\left(\mathrm{F}_{0}\right)$ of potato samples measured by a) the Walz monitoring-PAM device and b) by the PSI Open FluorCam device during storage. 

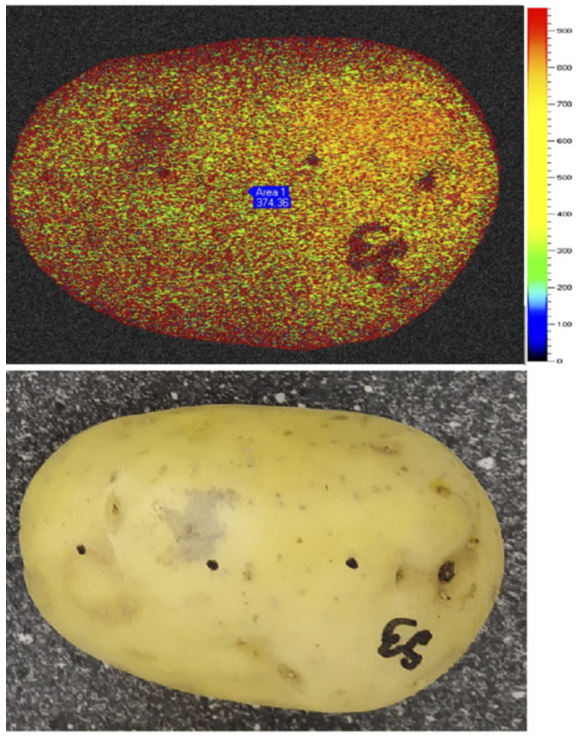

Day $0 \mathrm{~F}_{0}$ (above) and digital (below) image of initially yellow potato

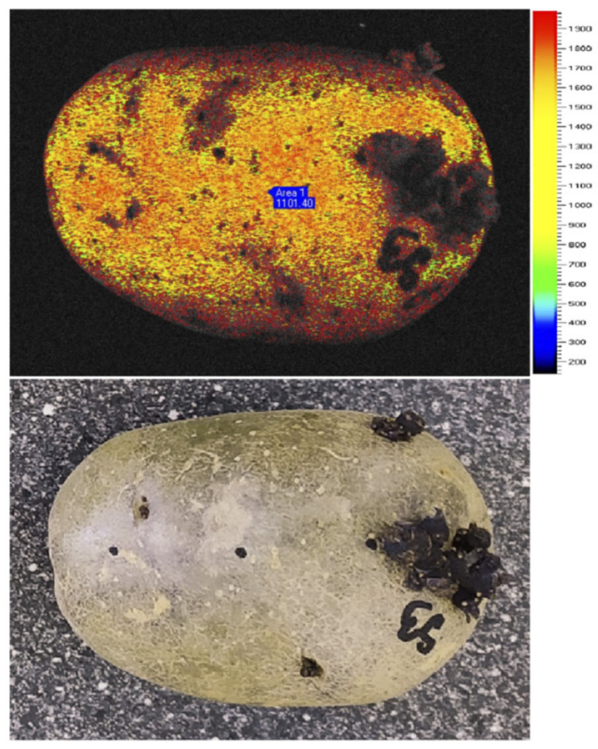

Day $59 \mathrm{~F}_{0}$ (above) image and digital (below) of initially yellow potato
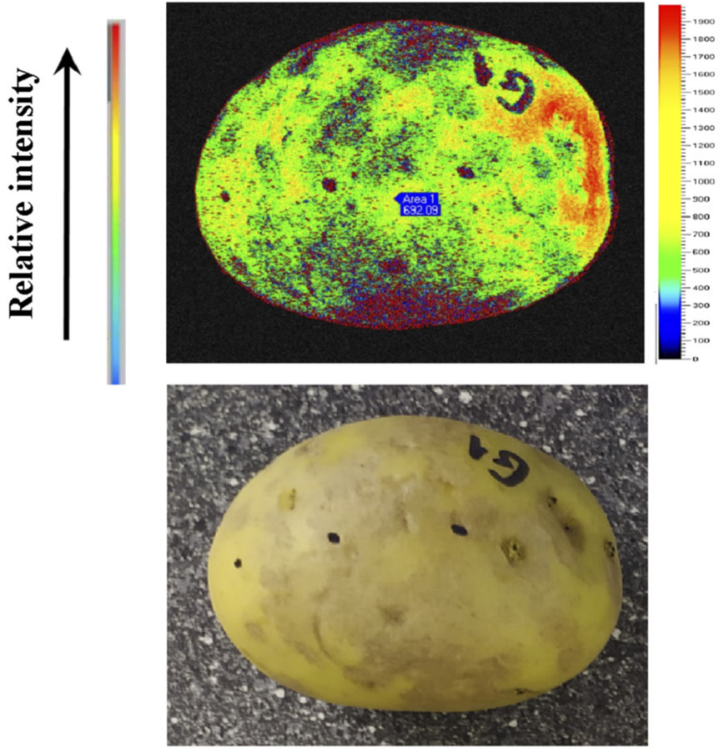

Day $0 \mathrm{~F}_{0}$ (above) and digital (below) image of initially spotted green potato
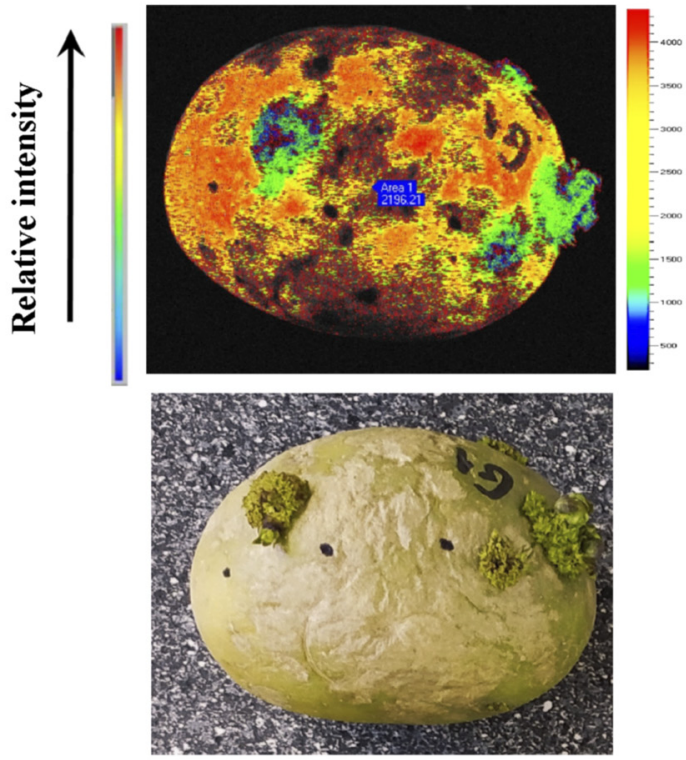

Day $59 \mathrm{~F}_{0}$ (above) image and digital (below) of initially spotted green potato

Fig. 7. Images of minimum chlorophyll fluorescence values $\left(\mathrm{F}_{0}\right)$ of potatoes measured by the PSI Open FluorCam device at the beginning (day 0) and at day 59 of storage. Colored relative intensity charts next to the false colored images indicate the recorded $\mathrm{F}_{0}$ intensities in the samples' matching photosynthetically active pixels. In these false colored images (resolution: 1360*1024 pixel), the redder is a pixel of the image, the greener is the area of interest, so the higher is the photosynthetically active chlorophyll content related fluorescence light emission sensibly captured by the device. The above shown relative intensity charts are automatically scaled providing a reference to the minimum and maximum intensities recorded in each of the pixels of the image. 
groups' chlorophyll fluorescence characteristics increased during the storage period suggesting the photosynthetically active chlorophyll content increase as it was shown earlier in the case of the DA-index ${ }^{\circledR}$ (Fig. 4). In the case of $\mathrm{F}_{\mathrm{m}}$ (Fig. 5a and b), the yellow group reached the initially spotted green group's level measured by the Walz monitoring-PAM device by day 7, and by day 9 measured by the PSI Open FluorCam device. Later, the $\mathrm{F}_{\mathrm{m}}$ practically did not change significantly, suggesting a stabilized level of photosynthetically active chlorophyll content formation (Fig. 5a and b).

Similarly to the case of $\mathrm{F}_{\mathrm{m}}$ values' change, the $\mathrm{F}_{0}$ value increased during the storage period. By day 7, the yellow group's $\mathrm{F}_{0}$ value reached that of the spotted green group (Fig. 6a and b).

After day 34, in the case of both groups the sunny side's $\mathrm{F}_{0}$ value was lower than that of the shaded side's. In the case of the yellow group, this difference was found significant from day 38 , measured by both of the used chlorophyll fluorescence devices (Figs 5 and 6).

In Fig. 7 the chlorophyll fluorescence images (representing the $\mathrm{F}_{0}$ values) of the initially yellow and spotted green samples (first row) and their day 59 values (second row) are shown in order to illustrate some of the chlorophyll fluorescence imaging results together with their matching digital images. Images were collected by the PSI Open FluorCam device.

The Walz monitoring-PAM and PSI Open FluorCam devices' results showed a similar pattern of change related to the visibly observed physiological changes (green surface coloration) documented also by the digital pictures taken and by the DA-meter ${ }^{\circledR}$ results (Fig. 4). Therefore, the relationship between the two measurement methods was investigated also. In Fig. 8, a close relationship between the results of the two methods is shown.

This relationship was found to be in the case of $F_{v}$ (variable chlorophyll fluorescence, $F_{m}$ $\mathrm{F}_{0}$ ) with $\mathrm{R}^{2}=0.7226$, in the case of $\mathrm{F}_{\mathrm{m}}$ with $\mathrm{R}^{2}=0.6159$ (data not shown) and in the case of $\mathrm{F}_{\mathrm{v}} /$ $\mathrm{F}_{\mathrm{m}}$ with $\mathrm{R}^{2}=0.6924$ (data not shown). This relationship suggests similarity between the results contrary to the different areas of interest, meaning in the case of Walz monitoring-PAM spotlike active areas (3 individual points per side) contrary to the PSI Open FluorCam's chlorophyll fluorescence imaging of the potatoes' sunny or shaded side (Figs 5 and 6).

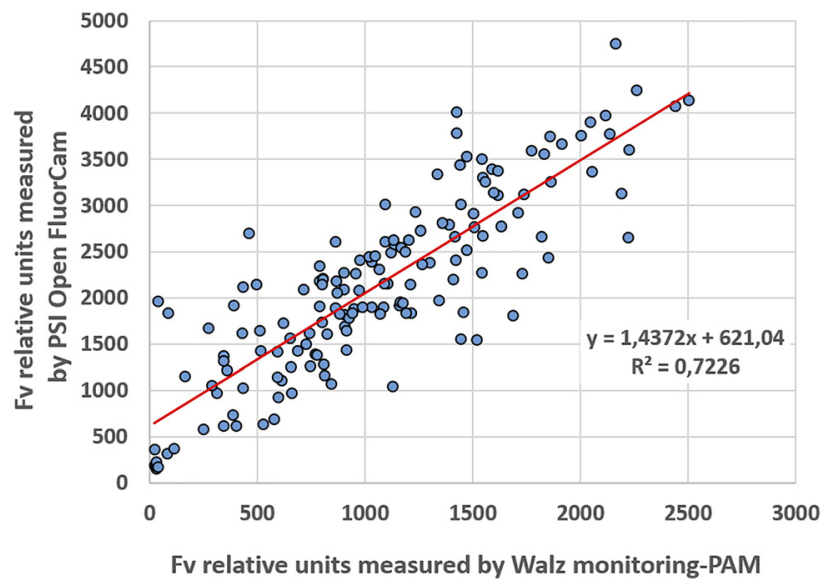

Fig. 8. Relationship between $\mathrm{F}_{\mathrm{v}}$ chlorophyll fluorescence values measured by Walz monitoring-PAM chlorophyll fluorometer and the PSI Open FluorCam chlorophyll fluorescence imaging system. 


\section{CONCLUSIONS}

The possibility of indirect detection of sunlight-induced formation of chlorophyll related human health hazardous compounds was investigated by the noninvasive detection of chlorophyll development during simulated shelf-life storage of market potato. Based on our preliminary results, the applied nondestructive devices such as Vis/NIR DA-meter ${ }^{\circledR}$, the monitoring-PAM and the chlorophyll fluorescence imaging fluorometers were found worthy of further noninvasive investigations (e.g. effect of sort and intensity of illumination, potato cultivars, [cold and/ or retail] storage conditions) of the postharvest chlorophyll formation based greening phenomena associated with potato solanine development.

\section{ACKNOWLEDGEMENT}

The project was supported by the European Union and co-financed by the European Social Fund (grant agreement no. EFOP-3.6.3-VEKOP-16-2017-00005); and by the Ministry for Innovation and Technology within the framework of the Higher Education Institutional Excellence Program (NKFIH-1159-6/2019) in the scope of plant breeding and plant protection researches of Hungarian University of Agriculture and Life Sciences (former Szent István University), Hungary.

\section{REFERENCES}

Abbasi, K. S., Masud, T., Qayyum, A., Ahmad, A., Mehmood, A., Bibi, Y., and Sher, A. (2016). Photoinduced changes in quality attributes of potato tubers during storage. Journal of Applied Botany and Food Quality, 89: 315-321.

Babazadeh, S., Moghaddam, P.A., Sabatyan, A., and Sharifian, F. (2016). Classification of potato tubers based on solanine toxicant using laser-induced light backscattering imaging. Computers and Electronics in Agriculture, 129: 1-8, ISSN 0168-1699.

Babazadeh, S., Moghaddam, P.A., Sabatyan, A., and Sharifian, F. (2020). Comparison of the laser backscattering and digital imaging techniques on detection of $\alpha$-solanine in potatoes. Journal of Agricultural Machinery, 10(1): 49-58.

Barceloux, D. G. (2009). Potatoes, tomatoes, and solanine toxicity (Solanum tuberosum L., Solanum lycopersicum L.). Disease-a-Month, 55(6): 391-402.

Bianchi, G., Scalzo, R.L., Testoni, A., and Maestrelli, A. (2014). Nondestructive analysis to monitor potato quality during cold storage. Journal of Food Quality, 37: 9-17, ISSN 1745-4557.

Ebrahimi, E., Mollazade, K., and Arefi, A. (2011). Detection of greening in potatoes using image processing techniques. Journal of American Science, 7(3): 243-247.

Felföldi, J., Kertész, I., Nagy, D., and Zsom-Muha, V. (2017). Nondestructive method for quality assessment of horticultural products. Progress in Agricultural Engineering Sciences, 13(1): 69-93.

Friedman, M. (2006). Potato glycoalkaloids and metabolites: roles in the plant and in the diet. Journal of Agricultural and Food Chemistry, 54(23): 8655-8681.

Gorbe, E. and Calatayud, A. (2012). Applications of chlorophyll fluorescence imaging technique in horticultural research: a review. Scientia Horticulturae, 38: 24-35. 
Grunenfelder, L. (2005). Physiological studies of light-induced greening in fresh market potatoes. Washinton State University, Department of Horticulture and Landscape Architecture. A thesis submitted in partial fulfillment of the requirements for the degree of Master of Science. https://research.libraries.wsu.edu: 8443/xmlui/handle/2376/321.

Grunenfelder, L. A., Knowles, L. O., Hiller, L. K., and Knowles, N. R. (2006). Glycoalkaloid development during greening of fresh market potatoes (Solanum tuberosum L.). Journal of Agricultural and Food Chemistry, 54(16): 5847-5854.

Kjær, A., Nielsen, G., Stærke, S., Clausen, M.R., Edelenbos, M., and Jørgensen, B. (2017). Detection of glycoalkaloids and chlorophyll in potatoes (Solanum tuberosum L.) by hyperspectral imaging. American Journal of Potato Research, 94: 573-582.

Machado, R.M.D., Cecilia, M., Toledo, F., and Garcia, L.C. (2007). Effect of light and temperature on the formation of glycoalkaloids in potato tubers. Food Control, 18: 503-508.

Matsuda, F., Morino, K., Miyazawa, H., Miyashita, M., and Miyagawa, H. (2004). Determination of potato glycoalkaloids using high-pressure liquid chromatography-electrospray ionisation/mass spectrometry. Phytochemical Analysis: An International Journal of Plant Chemical and Biochemical Techniques, 15: 121-124.

Ordóñez-Vásquez, A., Aguirre-Arzola, V., De la Garza-Ramos, M.A., Urrutia-Baca, V.H., and SuárezObando, F. (2019). Review article. Toxicity, teratogenicity and anti-cancer activity of $\alpha$-solanine: a perspective on anti-cancer potential. International Journal of Pharmacology, 15(3): 301-310.

Sanchez, P.D.C., Hashim, N., Shamsudin, R., and Nor, M.Z.M. (2020). Applications of imaging and spectroscopy techniques for non-destructive quality evaluation of potatoes and sweet potatoes: a review. Trends in Food Science \& Technology, 96: 208-221.

Sengül, M., Keles, F., and Keles, M.S. (2004). The effect of storage conditions (temperature, light, time) and variety on the glycoalkaloid content of potato tubers and sprouts. Food Control, 15: 281-286.

Tanios, S., Eyles, A., Corkrey, R., Tegg, R.S., Thangavel, T., and Wilson, C.R. (2020). Quantifying risk factors associated with light-induced potato tuber greening in retail stores. Plos One, 15(9): e0235522.

Tilahun, S., An, H.S., Hwang, I.G., Choi, J.H., Baek, M.W., Choi, H.R., Park, D.S., and Jeong, C.S. (2020). Prediction of $\alpha$-solanine and $\alpha$-chaconine in potato tubers from hunter color values and VIS/NIR spectra. Journal of Food Quality, 2020: 1-9, Article ID 8884219.

Ziosi, V., Noferini, M., Fiori, G., Tadiello, A., Trainotti, L., Casadoro, G., and Costa, G. (2008). A new index based on VIS spectroscopy to characterize the progression of ripening in peach fruit. Postharvest Biology and Technology, 49(3): 319-329.

Zsom, T., Strohmayer, E., Nguyen, L.P.L., Hitka, G., and Zsom-Muha, V. (2018). Chilling injury investigation by non-destructive measuring methods during banana cold storage. Progress in Agricultural Engineering Sciences, 14(s1): 147-158.

Zsom, T., Zsom-Muha, V., Nguyen, L.P.L., Nagy, D., Hitka, G., Polgári, P., and Baranyai, L. (2020). Nondestructive detection of low temperature induced stress on postharvest quality of kápia type sweet pepper. Progress in Agricultural Engineering Sciences, 12(1): 81-106.

Zsom-Muha, V. and Felföldi, J. (2007). Vibration behaviour of long shape vegetables. Progress in Agricultural Engineering Sciences, 3(1): 21-46.

Open Access. This is an open-access article distributed under the terms of the Creative Commons Attribution 4.0 International License (https://creativecommons.org/licenses/by/4.0/), which permits unrestricted use, distribution, and reproduction in any medium, provided the original author and source are credited, a link to the CC License is provided, and changes - if any - are indicated. (SID_1) 